\title{
ORGANIZACIÓN Y FUNCIONALIDAD DE LA PRODUCCIÓN LÍTICA EN UN NIVEL DEL PALEOLÍTICO MEDIO DEL ABRIC ROMANÍ. NIVEL JA (CAPELLADES, BARCELONA)
}

\author{
ORGANIZATION OF THE LITHIC PRODUCTION AND USE-WEAR ANALYSIS FROM \\ MIDDLE PALEOLITHIC SITE OF ABRIC ROMANÍ. LEVEL Ja (CAPELLADES, \\ BARCELONA, SPAIN)
}

\author{
KENNETH MARTÍNEZ $(*)$ \\ JOSÉ MARÍA RANDO $(*)$
}

\section{RESUMEN}

La intervención arqueológica del nivel Ja del Abric Romaní ha aportado una información muy valiosa para comprender los patrones conductuales de los últimos homínidos arcaicos. La reconstrucción de la organización de la producción lítica y los análisis funcionales indican una planificación a la hora de gestionar la materia prima y en el diseño de los útiles según tareas específicas. El registro arqueológico muestra una estructuración compleja de las ocupaciones en el interior del abrigo, así como una organización a escala regional de las ocupaciones. La explotación del entorno dependía principalmente de una gestión cuidada de la materia prima mediante el desplazamiento por el territorio de núcleos, como reserva de útiles, y de objetos retocados. Las lascas fueron útiles versátiles, trabajaron tanto madera como piel, y también participaron en actividades de carnicería. Por su parte, los denticulados fueron utilizados para trabajar madera, probablemente para elaborar puntas en este material. Por tanto, el presente artículo intenta comprender el modo de vida de las comunidades de neandertales sin compararlo con hipotéticos modelos conductuales de los homínidos modernos.

\footnotetext{
ABSTRACT

The fieldwork from layer Ja at Abric Romaní provides some interesting insights on the examination of patterns of late premodern hominid behavior. The reconstruction of châine opératoire and use-wear analysis point out planning

(*) Área de Prehistoria. Dpto. de Historia y Geografía. Universidad Rovira i Virgili. Plz. Imperial Tarraco, 1. 43005 Tarragona. España. Correo electrónico: paleo@ astor.urv.es kenneth@prehistoria.urv.es

El artículo fue remitido en su versión final el 27-I-2001.
}

in the consumption of raw materials and in the design of stone tools for specific tasks. The archaeological record shows complexity in the settlement system and intrasite context, likewise, the land use depends mainly on the curation of tools through transport of cores, like reserve of tools, and retouched tools. The flakes were versatile tools; working wood, hide and participating in butchering activities and denticulates were used mainly on wood, probably to make points. So far, this work seeks to understand Middle Paleolithic way of life in its own right without comparing it with a hypothetical model of modern behavior.

Palabras clave: Abric Romaní. Paleolítico Medio. Cadena Operativa. Análisis funcional. Organización ecosocial.

Key words: Abric Romaní. Middle Paleolithic. Châine opératoire. Use-wear analysis. Ecosocial human organization.

\section{INTRODUCCIÓN}

El actual debate sobre la complejidad organizativa de las comunidades de neandertales está muy ligado a las dos corrientes enfrentadas sobre la interpretación del cambio histórico que causó su desaparición. Ante una situación de mosaico de tecnocomplejos y poblaciones, más que el resultado de una mutación biológica que dotó a ciertas poblaciones de ventajas en la competencia intraespecífica, parece que un proceso social fue el que favoreció ciertas conductas, $\mathrm{y}$ a sus portadores, frente a otras (Zilhão y d'Errico, 1999).

En el Abric Romaní, el cambio cultural del Paleolítico Superior se registra en el nivel superior de 
la secuencia estratigráfica, que corresponde a un Auriñaciense. Este nivel fue excavado prácticamente en su totalidad a principios de siglo por el descubridor del yacimiento. En la actualidad, tan solo se conserva en dos testigos que corresponden a las columnas estratigráficas. Los análisis polínicos han relacionado las condiciones paleoclimáticas de este momento con el interestadial Hengelo. Por su parte, las dataciones de U/Th disponibles de las plataformas travertínicas que sellan el nivel dan unas fechas de entorno a $40 \mathrm{Ka} \mathrm{BP} \mathrm{y}$, la serie de dataciones por AMS del propio nivel arqueológico, da una cronología media de 36 Ka BP (Bischoff et alii, 1994; Giralt y Julià, 1996).

Explicar la organización ecosocial de las comunidades del Paleolítico Medio nos parece esencial como paso previo a valorar su complejidad y comparar las diferentes estrategias adaptativas de los grupos biológicos humanos (Conard y Adler, 1998). Este corpus nos permitiría reconocer en qué ámbitos se dieron los cambios y en qué grado.

Las estrategias adaptativas puestas en práctica por los homínidos arcaicos para procurarse los recursos necesarios para la subsistencia condicionó la organización de la producción lítica (Kuhn, 1989, 1998). La capacidad tecnológica de estas comunidades debió satisfacer la demanda de útiles de las características adecuadas y en el momento oportuno para garantizar el éxito de la explotación del entorno. Ello implica la existencia de una estrecha relación de dependencia entre los requerimientos subsistenciales y la gestión de la materia lítica.

La estructuración espacial y temporal de las diversas secuencias de producción del utillaje debieron estar en concordancia con las estrategias de movilidad de los grupos de homínidos, que en consecuencia organizaron el aprovisionamiento y transporte de materiales líticos. Numerosos trabajos han puesto de relieve esta relación para explicar la variabilidad tecnológica y tipológica de los conjuntos líticos (Geneste, 1988; Roebroeks et alii, 1988; Rolland y Dibble, 1990; Dibble, 1995).

De igual manera, una direccionalidad en la explotación de los recursos bióticos o un cambio en el carácter impuesto a la explotación provocará tratamientos económicos en la gestión y características técnicas de los objetos que deben reconocerse. En relación con ello, se han planteado estrategias adaptativas sustentadas en útiles expeditivos y en la planificación y cuidado en la fabricación del utillaje (Binford, 1980; Kuhn, 1992). A su vez, otros autores han relacionado diferentes modelos de talla o de retoque de objetos, o la intensidad en la explotación y en la configuración, para señalar la existencia de distintas estrategias de control del territorio (Marks, 1988; Kuhn, 1995). Desde grupos con una alta movilidad residencial, relacionada con una captación oportunista de los recursos, a grupos con una movilidad calificada como logística debido a la planificación de los desplazamientos.

Todas estas interpretaciones sobre la conducta socioeconómica de los homínidos arcaicos se sustentan metodológicamente en la capacidad de reconstruir el proceso de producción lítica. La excavación en extensión de la superficie de un nivel arqueológico y la recuperación de todo el registro en él contenido posibilita disponer de los materiales que convergieron en un lugar determinado durante el desarrollo de las actividades implicadas en las ocupaciones antrópicas.

A partir de las secuencias técnicas presentes y ausentes en el registro arqueológico, el yacimiento es' un referente del proceso de fabricación del utillaje a escala regional. Pero a su vez, la explotación del material lítico en el interior del asentamiento muestra el tratamiento económico dado a los recursos introducidos. Este tratamiento estará condicionado por la funcionalidad del asentamiento o la disponibilidad de recursos líticos en el entorno inmediato, pero que, en cualquier caso, son las respuestas humanas ante unas determinadas condiciones y deben reflejar la intencionalidad en el control del entorno (Carbonell et alii, 1992).

El trabajo que presentamos es un estudio sobre la producción lítica y su funcionalidad. El objetivo es reconocer las estrategias económicas de las comunidades humanas del momento y valorar el comportamiento humano en relación con el binomio necesidad y disponibilidad de útiles que las estrategias adaptativas pusieron en relación.

Para ello, se toma como punto de partida el estudio y reconstrucción de las cadenas operativas líticas, entendidas éstas como el proceso flexible que va desde la selección de la materia prima hasta el abandono del objeto, pasando por su gestión y uso, empleando, para ello, el conjunto de objetos recuperados (Guilbaud, 1995). A continuación, se ha aprovechado el proyecto de remontajes realizado sobre el material lítico (Vaquero et alii, 1996). Los remontajes son una herramienta que nos permite aproximarnos a las formas de organizar la producción en el interior de los lugares de ocupación y asociar materiales y áreas del asentamiento a un mismo momento sincrónico de ocupación. Ade-

T. P., 58, n. $^{\circ} 1,2001$ 
más, aportan información para valorar los posibles fenómenos posdeposicionales y permiten realizar inferencias técnicas al reconstruirse secuencias de talla (Cziesla et alii, 1990).

Por nuestra parte, se han seleccionado los grupos de remontaje más destacados; por la cantidad de elementos que los conforman, la amplitud e intensidad de secuencias técnicas identificadas y la dispersión de sus elementos por la superficie del nivel arqueológico, para, sobre ellos, realizar un estudio detallado sobre la organización y funcionalidad de estas secuencias técnicas.

Sobre estos grupos de remontajes se reconstruye el proceso productivo, se resitúan espacialmente las diversas secuencias técnicas sobre el área excavada y se realiza un análisis funcional sobre objetos seleccionados de cada grupo. Dicho estudio no pretende identificar únicamente actividades y materiales trabajados. Busca reconocer también aquellas morfologías que fueron utilizadas, si hubo variabilidad a la hora de utilizarlas y, sobre todo, observar si la funcionalidad dirigió la producción lítica. Ello se daría si reconocemos morfologías que son recurrentemente producidas para aprovecharlas en usos concretos. La conciencia de unas necesidades y de las morfologías que las resuelven implicaría la complejidad tecnológica de estos grupos humanos.

\section{EL ABRIC ROMANÍ}

El yacimiento se encuentra en la localidad barcelonesa de Capellades, en un estrecho valle que aprovecha el ríoAnoia, afluente del río Llobregat, para atravesar la Cordillera Prelitoral Catalana. En ese punto, se levanta, en el margen derecho, una construcción travertínica que forma un escarpe orientado hacia el este de una altura de $60 \mathrm{~m}$ sobre el actual lecho del río (Fig. 1).

En el edificio travertínico se formaron una serie de abrigos y cavidades que fueron visitados por comunidades paleohistóricas. Las ricas surgencias hídricas del lugar, fuertemente cargadas de carbonato disuelto, crearon las viseras y cubiertas de los abrigos al correr y saltar el agua de la plataforma travertínica buscando el río que corre a los pies.Así pues, la formación de plataformas travertínicas es el ambiente sedimentario básico del yacimiento, determinado por la cantidad de circulación hídrica en el interior del abrigo, que marcará sus posibilidades de ocupación entre momentos de encharca-



Fig. 1. Localización del Abric Romaní en el nordeste de la Península Ibérica, en la provincia de Barcelona.

miento o excesiva humedad y momentos secos. Aunque existen otros aportes, la formación de estas plataformas, con un ritmo sedimentario alto, limita la amplitud temporal de los palimpsestos, sellando los diferentes niveles antrópicos. A su vez, también permite una óptima conservación de evidencias arqueológicas poco comunes, como hogares y artefactos de madera (Carbonell y CastroCurel, 1992). El gran número de estructuras de combustión, en algunos casos delimitadas por bloques de travertino o aprovechando cubetas naturales, nos reafirma en la importancia que tuvo el uso del fuego en la organización de las actividades de las comunidades de Neandertales durante el Paleolítico Medio (Carbonell et alii, 1996).

El abrigo cuenta con una secuencia estratigráfica de casi $17 \mathrm{~m}$ de potencia, donde se ha contabilizado un mínimo de 27 niveles arqueológicos. Exceptuando el nivel superior, los restantes corresponden al Paleolítico Medio, con la base de la secuencia datada en $70 \mathrm{Ka} \mathrm{BP}$ (Burjachs y Julià, 1994). Los análisis polínicos indican una sucesión de cinco fases climáticas englobadas dentro de los Estadios Isotópicos 5, 4 y 3 . En esta secuencia diacrónica se constatan fluctuaciones climáticas. Los niveles inmediatamente por encima del nivel Ja en estudio corresponden al momento más frío y seco, con un paisaje estépico, que enmarcaría el subnivel Ja en un momento de empeoramiento acusado de las condiciones climáticas (Burjachs y Julià, 1994) (Fig. 2).

La vía de comunicación que crea el ríoAnoia en este punto, en el Estrecho de Capellades, es una ruta estratégica en los desplazamientos entre el litoral mediterráneo, hoy en día a menos de $50 \mathrm{~km}$, y el interior de la Península Ibérica a través de la Depre- 




Fig. 2. Estratigrafía sintética delAbric Romaní (Barcelona).

sión Central Catalana, inmediatamente aguas arriba del estrecho. A su vez, en este punto entran en contacto distintas realidades físicas con sus respectivos ecosistemas; la Cordillera Prelitoral, donde se encuentra el yacimiento, el valle del río Anoia, la Depresión Litoral Catalana, a donde se abre el río una vez atravesada la cordillera, y la Depresión Central Catalana de donde viene el río antes de penetrar en el estrecho. Esta posición geográfica permite que desde el abrigo puedan explotarse, en un radio de $15 \mathrm{~km}$, una variedad de ecosistemas que dan al lugar una riqueza de posibilidades. El mismo estrecho de Capellades, de una longitud de $7 \mathrm{~km}$ y de poco más de $3.5 \mathrm{~km}$ en su parte más ancha, al quedar resguardado favorece el desarrollo de ecosistemas más estables o el atenuamiento de condiciones severas.

Con respecto a los recursos líticos disponibles en la región, éstos son abundantes y de fácil localización. En el mismo estrecho hay formaciones prima- rias de cuarzo, en filones entre las pizarras silúricas de la Cordillera Prelitoral, y también calizas terciarias. Formaciones geológicas con afloramientos de sílex se han localizado, pero fuera ya del estrecho, a más de $10 \mathrm{~km}$ de distancia del abrigo. No obstante, estas formaciones son drenadas por el ríoAnoia y por ramblas subsidiarias, que acercan estos materiales al abrigo o los introducen en la red hídrica intensamente frecuentada por las comunidades de homínidos. Además, por la observación de superficies corticales en los materiales introducidos y las prospecciones realizadas, pensamos que el río y ramblas cercanas fueron las áreas principales de captación de materia prima.

En las distintas cavidades existentes se documentan evidencias de ocupaciones humanas de época prehistórica. Los primeros hallazgos arqueológicos se fechan a finales del siglo pasado, cuando un aficionado local, Amador Romaní i Guerra, se interesó por las posibilidades de la zona. En 1909 descubre e inicia los trabajos de excavación en el abrigo que lleva su nombre. Los resultados más destacados de esta primera fase de intervención corresponden a la excavación en extensión del nivel superior, denominado A, que se atribuye al tecnocomplejo auriñaciense arcaico, datado por U/Th entorno a $40 \mathrm{Ka}$ BP (Bischoff et alii, 1994). Con posterioridad, distintos proyectos de trabajo en su interior, con mayor o menor continuidad, afectaron al yacimiento con diversas catas y trincheras (Bartrolí et alii , 1995). Desde 1989, es el actual equipo de investigación de la Universidad Rovira iVirgili en Tarragona quien estudia las poblaciones que ocuparon la región, interesándose principalmente en la reconstrucción de la conducta de los homínidos. La metodología de excavación se ha adaptado a esta pretensión, interviniéndose en extensión la superficie de los diferentes niveles.

\section{NIVEL Ja}

La superficie del nivel en estudio se ha excavado, prácticamente, en su totalidad, que representa unos $240 \mathrm{~m}^{2}$ con las densidades de material más elevadas de toda la secuencia, 65.2 elementos $/ \mathrm{m}^{2}$. El nivel corresponde al último depósito arqueológico afectado por excavaciones anteriores, aunque tan sólo en $12 \mathrm{~m}^{2}$ de su superficie. La serie de dataciones por U/Th permiten situar este nivel entre los $49.3 \pm 1.6$ y los $50.4 \pm 1.6 \mathrm{Ka} \mathrm{BP}$ (Bischoff $e t$ alii, 1988). 
El nivel cuenta con un elemento sedimentario singular, una facies de caída de bloques procedentes de la cornisa y paredes del abrigo. Estos bloques delimitaron un espacio protegido óptimo para ser ocupado, cerrando la parte central del abrigo entre la pared y la línea de caída de la cornisa. En esta zona, la plataforma travertínica subyacente quedó deprimida, favoreciendo la formación de un ambiente deposicional palustre y de plataforma. Como consecuencia de ello, se pudo diferenciar, dentro del nivel arqueológico $\mathrm{J}$, dos subniveles, Ja y $\mathrm{Jb}$, separados por una plataforma travertínica. A su vez, el paleorelieve del nivel se completa con cinco espacios individualizados, o lóbulos, que crea la morfología cóncava de la pared del abrigo. Uno de estos espacios, el lóbulo 3, situado en el sector central de la pared, quedó prácticamente separado del resto al formarse una estructura travertínica que encerró un pequeño espacio de casi $5 \mathrm{~m}^{2}$. Sin duda, un lugar tan resguardado no pasó desapercibido durante las ocupaciones humanas (Lám. I).

Debido al alto grado de fracturación que afecta a los huesos, tan solo un 14\% de los elementos recuperados se han podido identificar. Sobresalen los restos pertenecientes a Cervus elaphus, Equus caballus y Bos primigenius, con el $81 \%$ del total. Aunque es más elevado el número de elementos óseos atribuidos a cérvidos, el NMI es superior en los équidos. Esta diferencia se debe a que en el abrigo se introducen carcasas casi completas de los primeros, mientras que, con respecto a los segundos y a los bóvidos, los restos del esqueleto poscraneal frente a los craneales son escasos. Por último, los restos óseos pertenecientes a carnívoros son muy escasos ( $>1 \%)$, aunque su presencia también se documenta con mordeduras sobre huesos, interpretadas como un acceso secundario, y en forma de coprolitos.

La distribución espacial del registro muestra como las mayores densidades de material se concentran en la zona interna, entre la pared y la línea de caída de bloques, justo el espacio más adecuado para ocupar al estar resguardado del exterior. En esta zona, además se han identificado la mayor parte de las 46 estructuras de combustión del nivel, que llegan a formar importantes áreas de combustión por la superposición y solapamiento de numerosos impactos térmicos (Fig. 3).

Las mayores densidades de material lítico corresponden a restos de talla asociados a hogares. Aunque no se ha identificado ninguna zona con acumulaciones porcentualmente destacadas de nú-



Lám. I. Vista del nivel Ja desde el lóbulo 1 o Este teórico delAbric Romaní (Capellades, Barcelona). Se puede observar la zona central delimitada entre la pared y los bloques de la caída de la cornisa y, a la izquierda, el lóbulo 3 separado del resto del abrigo por una construcción travertínica. En el centro de la imagen se ven los impactos de rubefacción de las estructuras de combustión.

cleos u objetos retocados, las zonas exteriores cuentan con índices similares, o en algún caso superior, de objetos retocados en relación con las acumulaciones principales del interior. Esta circunstancia puede deberse a que los procesos de explotación y los procesos de configuración tenían cadenas operativas diferenciadas por su objetivo, que hacía que no coincidiesen sus distintos momentos técnicos en el espacio ocupado. De igual manera, podemos plantear la selección de áreas marginales para realizar tareas intensas o especializadas. Así se interpreta la acumulación de bloques de caliza de distintos formatos recuperada en una zona externa del abrigo (Vaquero, 1999).

No obstante, el aspecto más destacable de la distribución espacial del registro consiste en una segregación del material según sus dimensiones. El material de pequeño y medio formato, tanto óseo como lítico inferior a $5 \mathrm{~cm}$, se concentra en la zona central, mientras que los restos de mayor tamaño se encuentran casi exclusivamente en la parte externa del abrigo, detrás de la línea de caída de bloques. De igual manera, las plaquetas travertínicas decimétricas, desprendidas de paredes y techo del abrigo, se encuentran, sin poderse atribuir a agente natural alguno, concentradas también en zonas externas marginales a las áreas principales de ocupación. En consecuencia, parece que en alguna de las ocupaciones se dio alguna actividad de limpieza que desplazó los materiales que estorbaban del área ocupacional a zonas secundarias (Vaquero, 1999) (Fig. 4). 


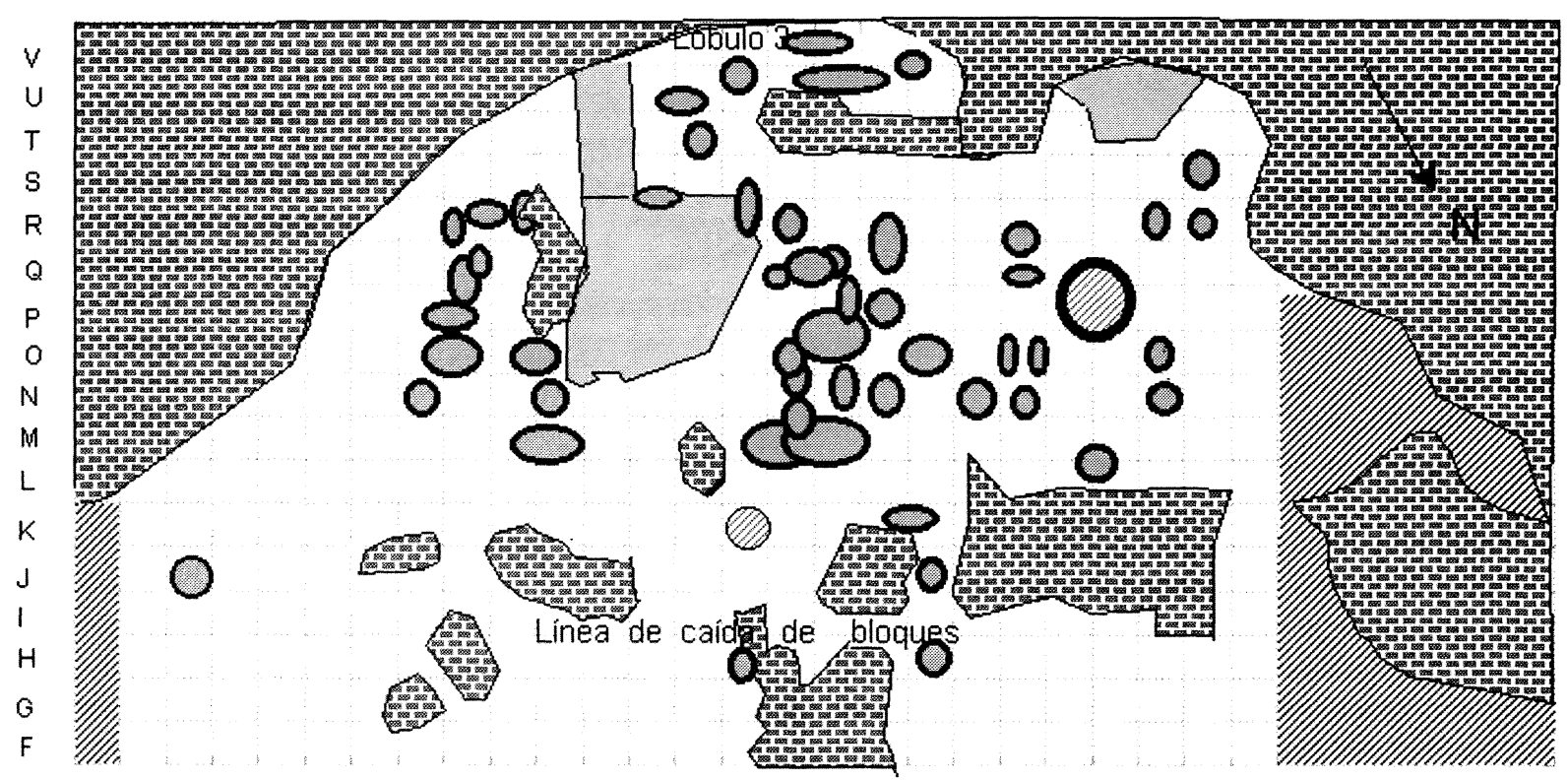

$\begin{array}{llllllllllllllllllllllllllllllllll}66 & 65 & 64 & 63 & 62 & 61 & 60 & 59 & 58 & 57 & 56 & 55 & 54 & 53 & 52 & 51 & 50 & 49 & 48 & 47 & 46 & 45 & 44 & 43 & 42 & 41 & 40 & 39 & 38 & 37 & 36 & 35\end{array}$





Fig. 3. A. Abric Romaní (Barcelona), planta general del nivel Ja y distribución de las estructuras de combustión identificadas. B. Planta de distribución espacial de todos los elementos arqueológicos recuperados (líticos, óseos y carbones).

Hasta el momento se han podido reconocer 108 remontajes, que agrupan a un total de 282 objetos líticos en 174 conexiones técnicas. La media de la longitud que separa a los objetos de las distintas conexiones es de $194.3 \mathrm{~cm}$ y tan solo un $11 \%$ de las conexiones señalan una separación superior a $\operatorname{los} 4$ $\mathrm{m}$. Por tipos de remontajes, son las fracturas, co- nexiones que refieren a accidentes de talla, las que presentan distancias menores entre los objetos, frente a las conexiones que remontan secuencias de explotación. En consecuencia, los remontajes permiten plantear que la disposición original del registro no se encuentra alterada y posibilita la interpretación de la intencionalidad en el desplazamiento de

T. P., 58, n. ${ }^{\circ} 1,2001$ 

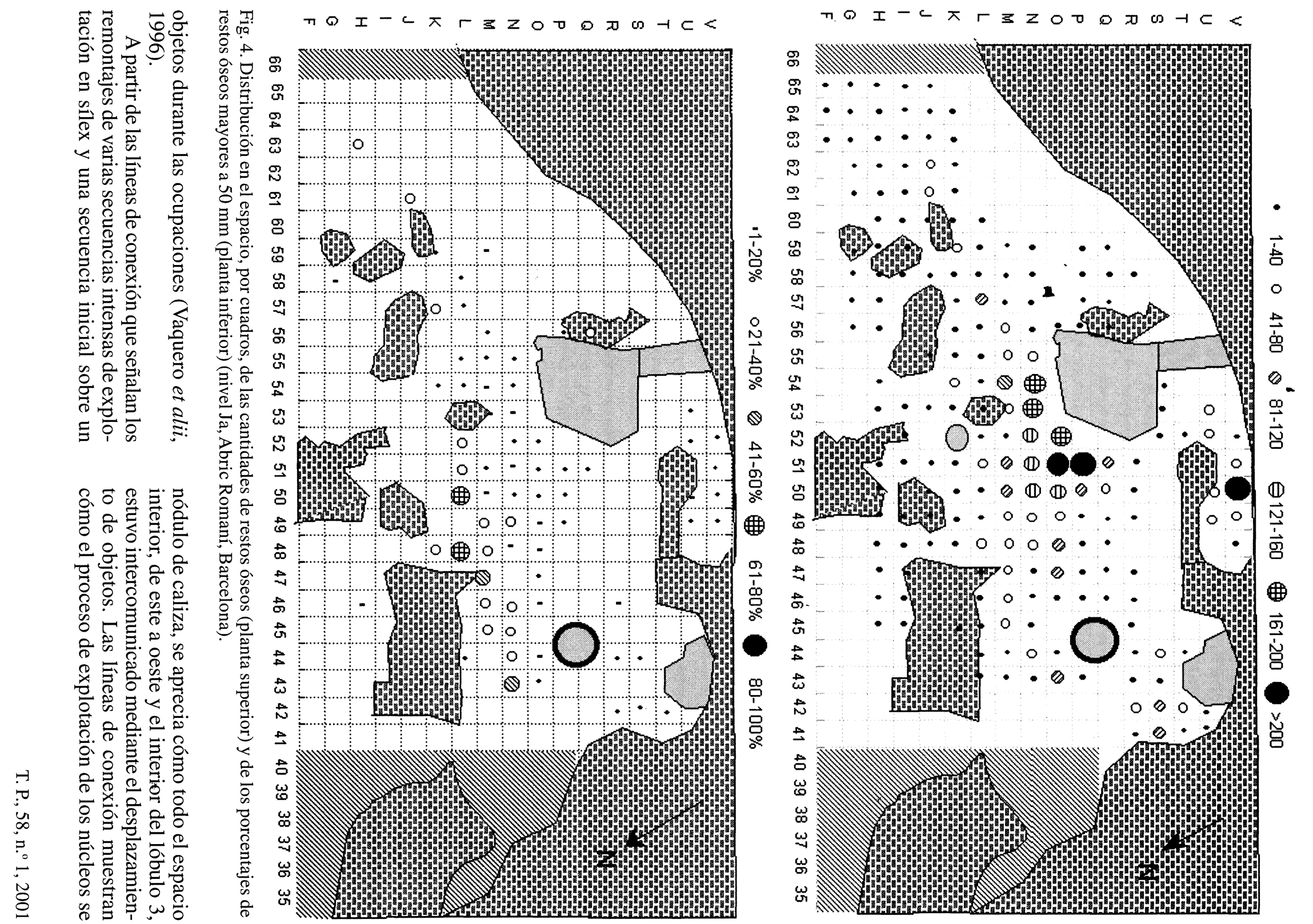




$\begin{array}{llllllllllllllllllllllllllllllll}66 & 65 & 64 & 63 & 62 & 61 & 60 & 59 & 58 & 57 & 56 & 55 & 54 & 53 & 52 & 51 & 50 & 49 & 48 & 47 & 46 & 45 & 44 & 43 & 42 & 41 & 40 & 39 & 38 & 37 & 36 & 35\end{array}$

Fig. 5. Planta de los remontajes de objetos en sílex del nivel Ja (Abric Romaní, Barcelona).

fragmentaba temporalmente en secuencias que se realizaban espacialmente en varios puntos del abrigo. El movimiento de estos objetos indica una estrecha relación entre las distintas áreas del interior, pero apenas muestra relaciones con la zona exterior, que queda como un área marginal y periférica de las ocupaciones, que se aprovecharía para acumular desperdicios (Fig. 5).

\section{ORGANIZACIÓN Y FUNCIONALIDAD DE LA PRODUCCIÓN LÍTICA}

\section{Características morfotécnicas de los objetos}

En el análisis sobre la gestión y tratamiento técnico de los recursos líticos se han utilizado los 4556 objetos mayores de $1 \mathrm{~cm}$ recuperados en el nivel. $\mathrm{Su}$ distribución por materias primas señala un predominio del sílex como material seleccionado, con un porcentaje superior al $70 \%$, seguido por la caliza y el cuarzo. Los tres materiales pueden considerarse autóctonos, aunque el sílex es el que tiene un área de captación más lejana, por lo que su mayor presencia denota una clara predilección por este material.Además, el cuarzo, abundantísimo en el entorno inmediato al abrigo, presenta una selección reducida, lo que sin duda demuestra el conocimien- to de las cualidades de los distintos materiales existentes en la zona y una selección y tratamiento económico en consecuencia.

Por categorías estructurales, hay un predominio de objetos que resultan de secuencias de explotación, ya que contamos con un $84 \%$ de lascas y fragmentos de lascas. Por materias primas, estos valores son válidos excepto en el caso de la caliza, que se reduce a un $41 \%$. Esta diferencia se debe a una diversidad de usos de este material, además de utilizarse en secuencias de talla. Con respecto a los objetos retocados, contamos con poco más de un $3 \%$. Según las materias primas, se observa una clara preferencia por el sílex, con un índice de configuración del $4 \%$, mientras que la caliza tan solo cuenta con un $1 \%$ (Tab.1).

Como se puede deducir de los datos, el sílex es utilizado exclusivamente como base de secuencias de talla, mientras que la caliza, por ejemplo, es la materia prima seleccionada para las Bases Naturales. Estas presentan una variedad de volúmenes, por lo que además de servir como percutores o machacadores de huesos, como reflejan los estigmas en sus superficies, existen bloques de mayores dimensiones sin ninguna intervención. La interpretación de su uso debe pasar por la contextualización de estos objetos con otros elementos del registro arqueológico, como el hecho de que muchos de ellos 


\begin{tabular}{|l|c|c|c|c|c|c|c|}
\hline & SILEX & CALIZA & CUARZO & CUARCITA & GRANITO & PIZARRA & TOTAL \\
\hline LASCA & 1.983 & 173 & 97 & 2 & 1 & - & 2.256 \\
\hline FRAGMENTO LASCA & 1.146 & 113 & 335 & 1 & - & - & 1.595 \\
\hline NÚCLEO & 49 & 2 & 5 & - & - & - & 56 \\
\hline CONFIGURADO & 138 & 4 & 6 & - & - & - & 148 \\
\hline EXPLOTACIÓN-2G & 22 & 15 & 2 & - & - & - & 39 \\
\hline BASE NATURAL & - & 27 & 1 & - & - & - & 28 \\
\hline FRAGMENTO & 11 & 351 & 27 & - & 1 & 44 & 434 \\
\hline TOTAL & 3.349 & 685 & 473 & 3 & 2 & 44 & 4.556 \\
\hline
\end{tabular}

Tab. 1. Distribución de los objetos líticos mayores a $1 \mathrm{~cm}$ según la materia prima y la categoría estructural (nivel Ja, Abric Romaní, Barcelona). Explotación 2G; Lasca explotada.

se encuentran asociados a hogares y presentan fracturas térmicas.

La mayor parte de estos objetos en caliza corresponden a Bases Naturales fracturadas. Su observación permite concluir que estas fracturas se produjeron durante el uso de estos objetos para golpear. Asímismo, en muchos casos, una vez fracturadas sirvieron como base de una corta secuencia de explotación, utilizando como superficie de intervención el plano horizontal, explotado preferentemente de manera unifacial.

Con respecto a las características morfotécnicas de las BP o lascas, estas cuentan mayoritariamente con superficies talonares del tipo plataforma y apenas presentan preparación de la cara talonar, con tan solo un 3\% de talones multifacetados, casi todos ellos en objetos de sílex. Igualmente, las caras dorsales presentan escasos negativos de levantamientos anteriores, con tan solo un $13 \%$ de objetos con más de cuatro levantamientos en la superficie dorsal. Habría que destacar la amplia presencia de lascas desbordantes, conocidas también como bordes de núcleo. Este tipo de morfología se puede obtener de manera sistemática mediante estrategias de explotación bifaciales centrípetas. A su vez, el índice de alargamiento muestra la ausencia de láminas, ya que tan solo un $3 \%$ de los objetos presentan un alargamiento igual o superior a 2 .

En las características técnicas de las lascas no se observan diferencias dependiendo de la materia prima. Las diferencias observadas pueden interpretarse como fruto de las propias características físicas de cada uno de los materiales. Por ejemplo, en sílex se observa una presencia mayoritaria de bulbos marcados frente a una presencia dominante en cuarzo de bulbos difusos, algo que sin duda se debe a la flexibilidad de las rocas. Por tanto, diríamos que existe un mismo tratamiento técnico, independientemente de la materia prima, a la hora de explotar el material.

No obstante, existe una diferencia que tiene implicaciones en la reconstrucción del proceso productivo. En las lascas en caliza hay una amplia presencia de superficie cortical, tanto en la cara dorsal como talonar, en comparación con los otros dos materiales. La baja presencia de córtex en cuarzo se explica porque este material se recoge en los depósitos de vertiente, bajo las formaciones primarias, por lo que la erosión y rodamiento no llegan a ser importantes. Pero tanto el sílex como la caliza se recogen en forma de nódulos en los cursos fluviales, por lo que la diferencia debe entenderse como cuantitativa debido a la distancia entre las zonas de captación de ambos materiales. Dado que la selección de la caliza es local, en el abrigo están presentes las secuencias iniciales de explotación de los núcleos. Por el contrario, el sílex es recogido en distancias mayores, por lo que el tiempo transcurrido hasta la introducción y la cantidad de intervenciones que sufrieron previamente los núcleos de este material fue mayor. Esta interpretación se refuerza por la mayor presencia cortical, entre los objetos de sílex, de aquellos de mayores dimensiones que se obtienen en las secuencias iniciales.

Se ha podido identificar un criterio a la hora de seleccionar los soportes a configurar, BN2G. Consiste en la selección de los objetos de mayores dimensiones y, sobre todo, de objetos carenados; aspecto este último que destaca, aun más, entre los objetos seleccionados de menor longitud. Igualmente existe una importante presencia de lascas desbordantes entre los objetos retocados; estas las- 
cas, por su asimetría lateral, presentan un espesor importante y, a la vez, una morfología muy adecuada para el modelo de configuración dominante en el nivel.

Este modelo dominante de configuración, con una representación del $88 \%$, corresponde al de denticulados y muescas, con una presencia testimonial de retoque continuo o raederas. Las zonas preferentemente configuradas son los laterales, sobre todo el lateral izquierdo, y en pocos objetos se observa más de una zona afectada, por lo que la intensidad de configuración puede considerarse reducida. Además, en la mayoría de los objetos, la configuración es menor que la mitad del perímetro.

Entre los objetos retocados existe una presencia cortical destacada, si se pone en relación con la escasa entre las lascas. Esto se debe a que, como ya se comentó, los soportes preferentemente seleccionados para configurar son objetos de grandes dimensiones, que son los que cuentan con mayor superficie cortical. Estos grandes soportes se obtienen en las secuencias iniciales de explotación de los núcleos, secuencias que para el sílex están poco representadas dentro del abrigo, por lo que parece que los objetos retocados entran ya configurados del exterior.

Por último, un número importante de productos de talla también es seleccionado pero, por la profundidad de los negativos de las extracciones, más que por la configuración de sus laterales parece que sufrieron una explotación volumétrica, BN2GE. Este aprovechamiento se observa exclusivamente en sílex, por lo que parece que estaríamos frente a una utilización que maximiza este material. La organización de la explotación de estos objetos es similar a la observada en los núcleos, que pasaremos a describir, aunque menos intensa y sistemática, debido a sus reducidas posibilidades volumétricas.

Un aspecto destacado entre los núcleos, BN1G, es que no se abandonan hasta que están agotados. Esto nos permite conocer en qué momento su explotación deja de ser posible, ya sea porque no se puede mantener la organización en la explotación o porque los productos obtenidos dejan de ser resolutivos. Las dimensiones de las últimas extracciones corresponden a lascas de $2 \mathrm{~cm}$ de longitud, que sería el límite útil de los filos de las lascas.

La explotación de los núcleos se organiza mediante la selección del plano horizontal como superficie de intervención, que es explotado bifacialmente al dividir el objeto en dos superficies, que son reducidas sistemática y recurrentemente. Existe algún núcleo trifacial que, a la misma estructura básica señalada, suma algunas extracciones desde el plano transversal explotando el plano sagital y dos núcleos multifaciales que, por sus reducidas dimensiones, pueden considerarse como un aprovechamiento máximo de sus posibilidades que descompuso la estructura bifacial.

Así pues, el modelo de explotación dominante corresponde con uno de los dos más comunes de este periodo cronocultural: los núcleos discoides (Boëda, 1993). No obstante, considerando el ángulo y la intensidad de explotación de las caras existe una variabilidad que debe considerarse. Así, por ejemplo, podemos distinguir entre núcleos bifaciales centrípetos simétricos y asimétricos, cuando ambas caras son explotadas con un ángulo simple o una de ellas es explotada con ángulo plano frente al ángulo simple de la otra superficie. Ante esta diferencia obtendríamos morfologías bicónicas o cónicas. A su vez, algunos núcleos asimétricos presentan una jerarquía al observarse una explotación cuidada e intensa de una de las superficies, mientras que la otra recibe extracciones que corrigen las convexidades para proseguir la explotación de la cara escogida.

No obstante, la propia dinámica continua de las secuencias de explotación no descarta que esta simetría o asimetría, o la jerarquía entre las caras no pueda ir construyéndose y destruyéndose a lo largo de la explotación de un mismo núcleo. En definitiva, existe un único modelo conceptual de organización volumétrica de los núcleos para su explotación, ya que se utiliza indistintamente en cualquiera de las materias primas y tanto para explotaciones intensas o marginales (Fig. 6).

\section{Composición y desarrollo técnico del proceso de producción}

Los resultados del análisis morfotécnico de los objetos líticos y de la composición y desarrollo técnico de los procesos de gestión de la materia lítica identificados en el nivel pueden resumirse de la siguiente manera. Los nódulos de caliza son utilizados como percutores o machacadores de huesos y no se ha documentado ninguna configuración sobre canto o sobre grandes lascas. Los soportes únicamente son aprovechados para explotarse volumétricamente en vistas a obtener lascas y, basándonos en la organización de esta explotación, se ha identificado un único modelo: el bifacial centrípeto. 


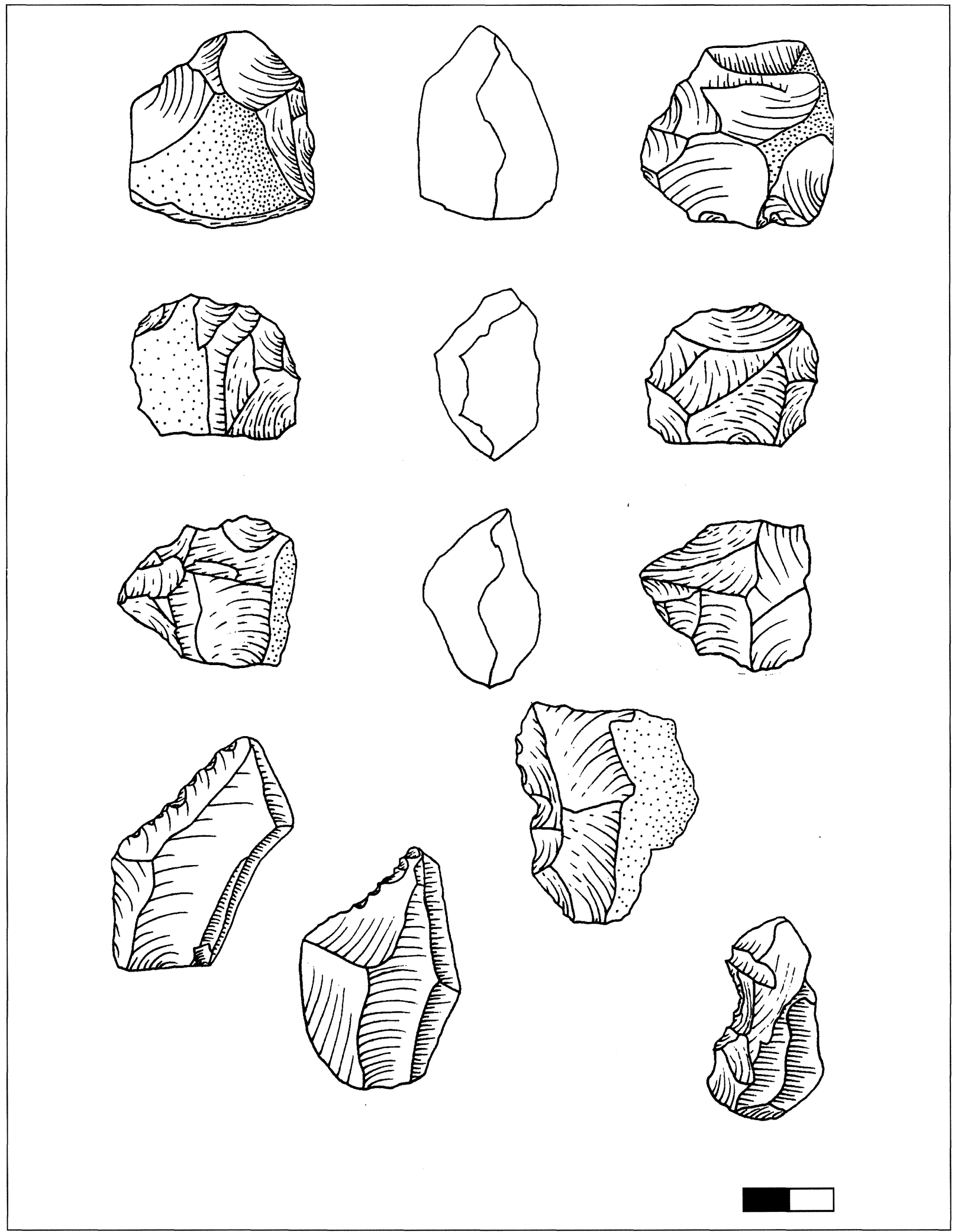

Fig. 6. Muestra de núcleos y objetos configurados del nivel Ja (Abric Romaní, Barcelona).

T. P., 58, n. $^{\circ} 1,2001$ 
A raíz de la plasmación física de este modelo conceptual resultan dos tipos de núcleos estructurados mediante el mismo método: núcleos bifaciales centrípetos simétricos y bifaciales centrípetos asimétricos. La explotación de los núcleos organizados según este método es intensa, pues los núcleos no se abandonan hasta su agotamiento y, a partir de los remontajes identificados, parece que este método se configuró desde el inicio de la explotación. Las lascas obtenidas en estas secuencias fueron funcionalizadas, como se comentará en el apartado correspondiente, y además, algunas fueron explotadas en segunda generación, para utilizar también sus productos o, configuradas, generando habitualmente un borde con delineación denticulada.

En definitiva, toda la producción de útiles líticos se generó a partir de la aplicación de un único método de explotación, suficientemente flexible para, según las necesidades y las posibilidades del núcleo, aprovecharlo al máximo sin romper la estructura. De ahí, la variabilidad notable que se refleja en los núcleos estudiados.

Esta variabilidad morfotécnica de los núcleos debe relacionarse con la utilización de útiles líticos en multitud de acciones. La perfecta adecuación de los modelos morfopotenciales de las lascas con las actividades que desarrollaron los homínidos hizo que los procesos de explotación volumétrica fuesen las secuencias técnicas principales a la hora de proporcionar útiles. De ahí que, dada la diversidad de actividades a realizar, la explotación fuese lo suficientemente flexible como para adecuarse a cada exigencia y obtener así los productos más idóneos para cada cometido.

Por contra, la escasa variabilidad en los modelos morfopotenciales identificados en las configuraciones, donde dominan ampliamente las delineaciones denticuladas, puede relacionarse con una escasa dependencia en la configuración para realizar satisfactoriamente las distintas actividades, ya que se solventarían con los filos naturales de las lascas. Pero alguna actividad sí precisó de un objeto especializado. Se ha identificado un modelo de soporte para configurar un objeto carenado y en donde se opone al filo denticulado un borde abrupto, como en el caso de las lascas desbordantes. Este objeto es muy capaz en acciones transversales para trabajar materiales duros. Como los diedros cóncavos no se obtienen habitualmente en los filos naturales de las lascas, hemos de considerar que la necesidad de este tipo de objetos mediante la configuración de denticulados debió ser lo suficiente- mente importante como para que fuese el único modelo de útil predeterminado.

En consecuencia, se puede concluir que existe una variabilidad en las secuencias de explotación, ya que deben generar una producción capaz de participar en distintas actividades y, por contra, existe una especialización en la configuración de filos denticulados para acciones transversales (Fig. 7).

\section{Movilidad externa de los objetos}

El abrigo fue un punto de referencia espacial en la sincronía de estas comunidades y en él convergieron objetos de distintos procesos técnicos. A partir de las secuencias técnicas presentes o ausentes en el interior podemos reconocer la estructuración espacial y temporal en el consumo de los recursos líticos, que ponemos en relación con la estructuración de las actividades productivas de estas comunidades a escala regional.

La caliza entra dentro del abrigo en forma de nódulos de río apenas intervenidos o como grandes lascas. Una vez introducida, dependiendo de su calidad, se aprovechó la masa de algunos nódulos como objetos contundentes para golpear. Los percutores no se abandonan a menos que se hayan fracturado, momento en que son reaprovechados, ya que son objetos que en muchos casos deben satisfacer exigencias personales. Las calizas de mejor aptitud para la talla fueron aprovechadas como núcleos, identificándose en el interior las secuencias iniciales de la explotación. En muy pocos casos se han recuperado estos núcleos, ya que no se habrían consumido y fueron exportados para participar en actividades en otros lugares.

Con respecto al cuarzo, ya se ha comentado que es la materia prima más abundante y disponible en el entorno inmediato. Es introducido, principalmente, en forma de plaquetas recogidas en los depósitos de vertientes de los alrededores. Su reducida presencia cuantitativa en el abrigo indicaría que su gestión no jugó un papel estructural en el aprovisionamiento de útiles. De igual manera, se observa una explotación poco cuidada de este material, con una escasa configuración de los núcleos para su explotación y sin aprovecharse al máximo sus volúmenes. Su gestión está constreñida al ámbito directo del abrigo, con una selección y abandono muy cercanos temporal y espacialmente.

Por su parte, el sílex es la materia prima que sufre procesos técnicos más prolongados e intensos.

T. P., 58, n. $^{\circ} 1,2001$ 
MATRIZ MORFOGENÉTICA; Proceso técnico de producción lítica



Fig. 7. Matriz Morfogenética, se representa la composición y desarrollo de los procesos técnicos identificados en el registro lítico del nivel Ja (Abric Romaní, Barcelona).

Su gestión es sumamente más cuidada y no se abandonan los núcleos hasta que no están completamente agotados.Además, al ser la materia prima menos abundante en la zona, su intensa selección implica que su disponibilidad fue fundamental en las estrategias de adaptación.

Los objetos en sílex fueron introducidos en el abrigo como núcleos, en distintos momentos de su explotación, en forma de grandes lascas, como objetos configurados y extrañamente para la diacronía de niveles del abrigo, en forma de bloques no intervenidos, como si se pretendiese abastecer ocupaciones que se prolongarían en el tiempo con reservas de un material escaso en la zona. Es interesante comprobar cómo los objetos retocados, denticulados, con frecuencia entran desconectados de las secuencias técnicas en que se obtuvieron. Esta observación obliga a considerar a los denticulados como objetos que participaron en las estrategias de desplazamiento de estos homínidos por el territo- rio, a diferencia de otras opiniones (Geneste, 1988; Kuhn, 1992). De todas maneras, aún queda por desvelar si las secuencias de configuración se realizaron durante el desplazamiento para reavivar las lascas utilizadas o para aprovechar cierto recurso cuya explotación ya se preveía de antemano en la zona del abrigo.

Una vez en el interior del abrigo se realizaron todas las secuencias técnicas posibles: explotación de los núcleos, configuración de lascas e incluso la explotación de alguna de ellas. El aspecto más destacado es que el proceso de producción en sílex está fragmentado espacial y temporalmente, ya que prácticamente no se ha podido reconstruir un proceso de explotación completo dentro del abrigo, donde destacan las fases finales, de ahí que se recuperen bastantes núcleos agotados. Incluso, aquellas secuencias más completas están segmentadas espacialmente entre distintas zonas del abrigo.

Es destacable el papel estructural que juegan los 


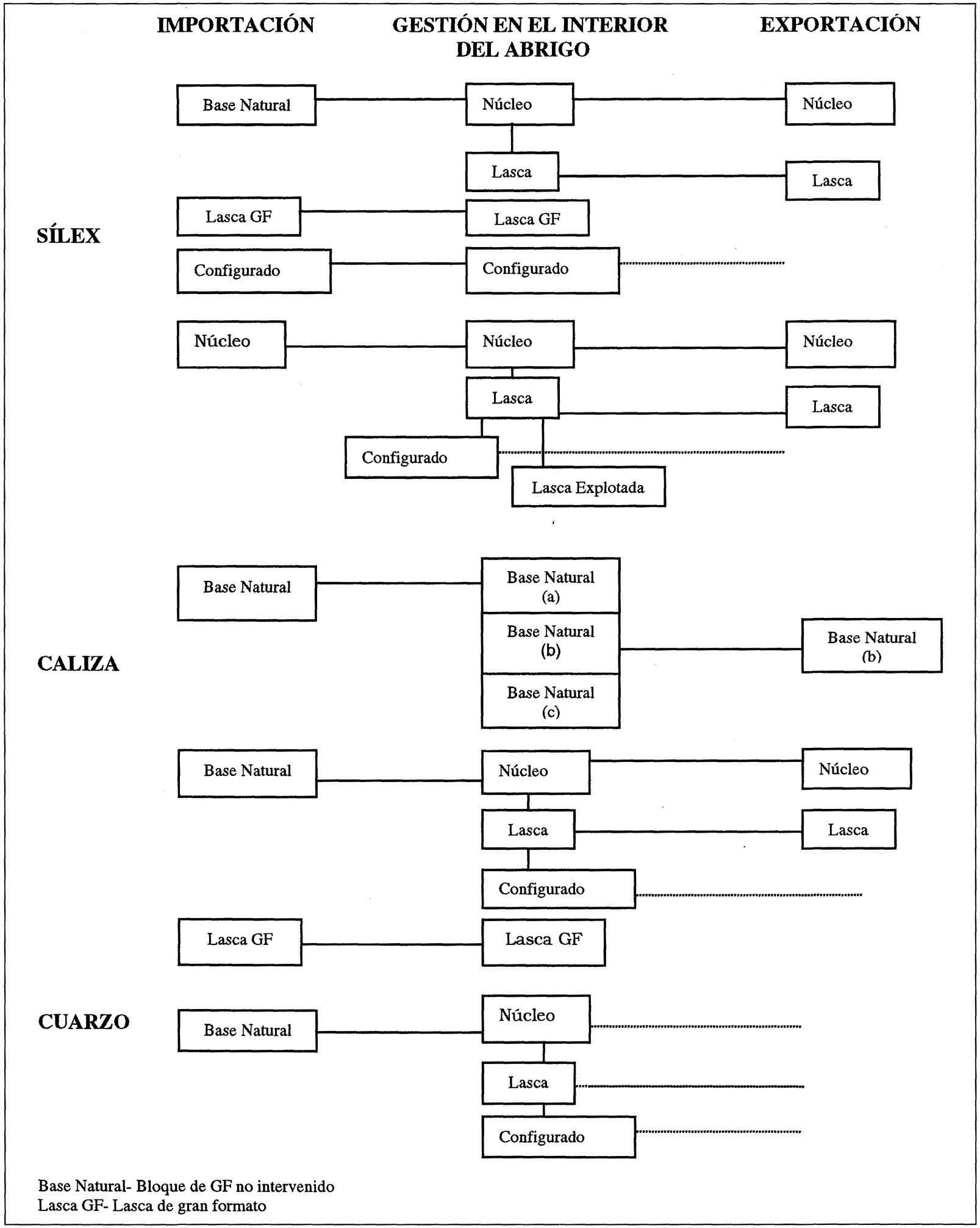

Fig. 8. Matriz de Movilidad, se representa la organización espacial y temporal de los procesos técnicos tomando como referencia el abrigo. Se sitúan antes y después aquellas secuencias que debieron realizarse en el exterior (Abric Romaní, Barcelona).

T. P., 58, n. $^{\circ} 1,2001$ 
núcleos como reserva de objetos para usar, que indica la conciencia de unas necesidades futuras por su dilatada gestión y, que junto a percutores y algún objeto configurado, formarían parte del utillaje personal empleado en los desplazamientos para responder a cualquier contingencia (Kuhn, 1992). En definitiva, se observa una organización de la producción diferida espacial y temporalmente a nivel regional, que podemos relacionar con grupos humanos con una gran movilidad en sus estrategias adaptativas (Fig. 8).

\section{Estudio funcional}

En este campo de investigación, la interpretación del proceso de formación de las alteraciones en la superficie de los objetos por su uso ha sido el principal foco de atención. La discusión se ha planteado entre una corriente que atribuye la causa de las deformaciones a un proceso abrasivo y otra que sitúa la génesis en un proceso aditivo (Jardón, 1990; Keeley, 1980; Odell, 1979). Este estudio se ha llevado a cabo utilizando un modelo teórico que considera las deformaciones como el resultado del esfuerzo de presión, fricción y temperatura a que es sometido el útil durante el trabajo (Sala et alii, 1998). Como consecuencia, la superficie de la roca responde fracturándose o deformándose mediante un comportamiento plástico. La primera respuesta, abrasiva, permite reconocer la cinética de la acción a través de estrías o desconchados. Por su parte, la deformación plástica es la variable que se considera determinante para diagnosticar los materiales trabajados. Este tipo de deformación resulta de la redeposición del sílice de la roca, en estado fluido debido al esfuerzo, sobre la superficie del objeto.

Para la observación microscópica de los bordes de los objetos se ha utilizado un Microscopio Electrónico de Barrido y la exploración se ha realizado a una profundidad de 1000 aumentos.

En los estudios funcionales realizados hasta la fecha sobre industrias del Paleolítico Medio se destaca el carácter polifuncional de los objetos (Anderson-Gerfaud, 1990; Beyries, 1987). Entre los materiales trabajados reconocidos abundan la madera y la carne y, aunque en menor porcentaje, también se ha reconocido la intervención sobre herbáceos y piel. En cualquier caso, parece que no se ha identificado ninguna relación estrecha entre la forma del útil y su función, aunque sí se ha observado, en varios yacimientos, que sobresalen unas formas y unos usos que puede atribuirse a la especialización funcional del asentamiento (Beyries y Boëda, 1983; Roebroeks et alii, 1997; Texier et alii, 1998)

La muestra para el estudio funcional ha partido de la elección de aquellos grupos de remontajes más destacados. Grupos que incluían las distintas secuencias de talla identificadas en el abrigo: explotación inicial y final de núcleos, secuencias casi completas, explotación de lascas y también objetos retocados, algunos configurados en el mismo abrigo y otros que entraron ya configurados. Del total de esos seis grupos de remontajes, uno corresponde a objetos en caliza y el resto en sílex. Para este análisis se han eliminado los objetos inferiores a $1 \mathrm{~cm}$ de longitud y aquellos con morfologías, a priori, sin capacidad de intervención. El grupo de remontaje más numeroso cuenta con 18 objetos y el menor con 3 , y la longitud mayor entre los objetos que forman las distintas conexiones identificadas es de $925 \mathrm{~cm}$ y la menor de $21.8 \mathrm{~cm}$. En total, 31 objetos repartidos entre: 19 láscas, 11 objetos retocados y una lasca explotada como núcleo (Fig. 9).

Es una muestra reducida con respecto al total de objetos recuperados en el nivel. No obstante, es una aproximación válida porque el estudio pretende valorar el grado de intencionalidad en la ejecución de las distintas secuencias técnicas. Como la producción de útiles sustentó las estrategias adaptativas de estas comunidades, este papel estructural implica que la organización de la producción debe mostrar un carácter recurrente, reconocible en todas y cada una de las secuencias técnicas, incluidas las seleccionadas.

Los resultados obtenidos respecto al total de objetos analizados se desglosan de la siguiente manera. En 6 no se ha podido reconocer ninguna deformación atribuible al uso. Corresponden a 5 lascas -2 de caliza - y a un denticulado. Han sido utilizados en los tres movimientos posibles, en acciones de cortar, raspar y rebajar material. Entre los posibles materiales trabajados se han identificado madera, vegetales herbáceos, biomasa animal y piel seca. Ello unido a los movimientos identificados apuntaría a actividades de: cortar, raspar y rebajar madera, cortar herbáceos, cortar biomasa animal blanda, despellejar, descarnar y raspar piel seca. En total, se han identificado 14 objetos que han trabajado vegetales, 9 en actividades de carnicería y 2 para raspar piel.

Esta mayor representación de deformaciones atribuidas al trabajo con madera muestra la importancia que tenía este recurso para la fabricación de 


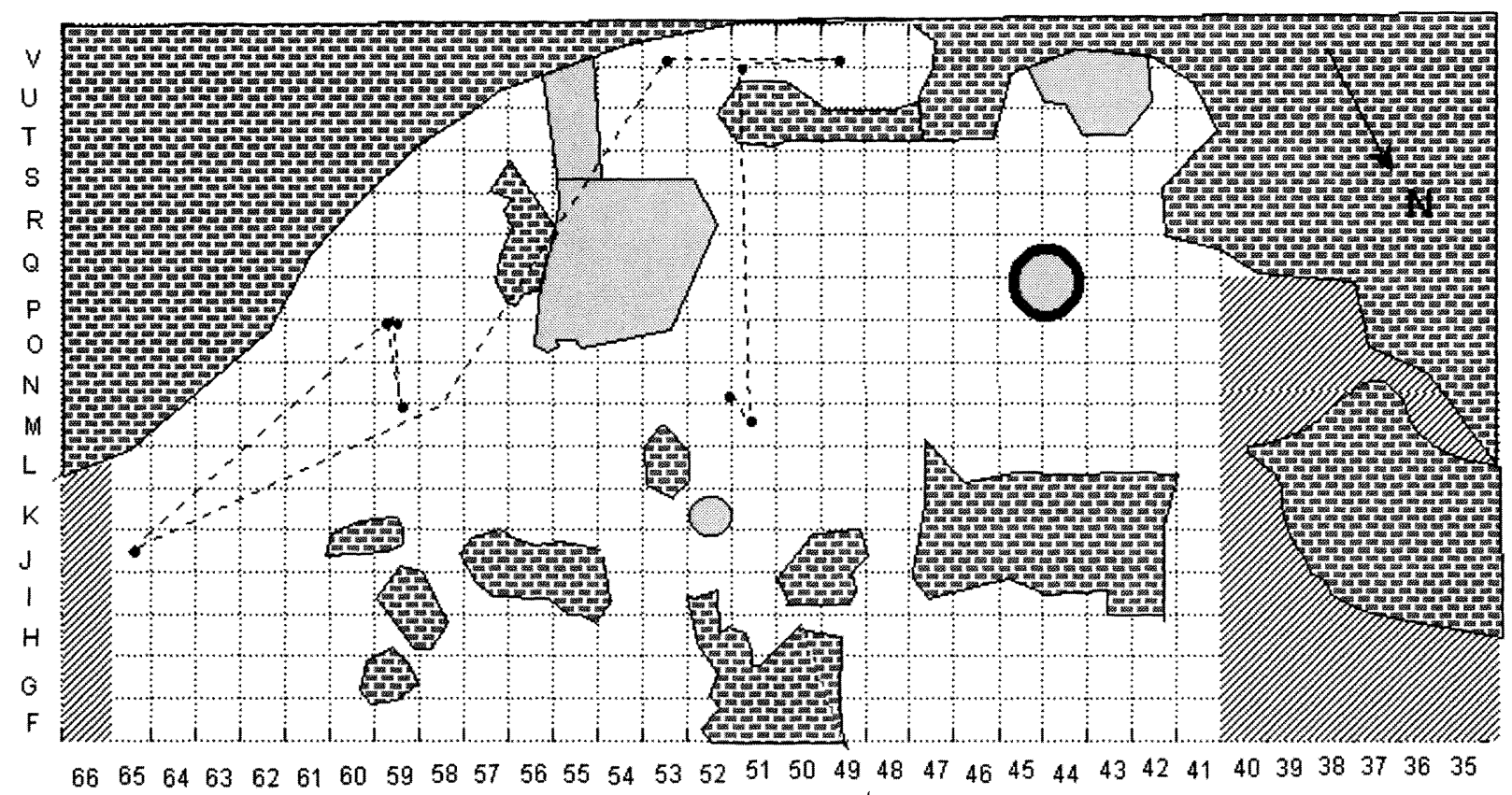

Fig. 9. Planta de la distribución espacial de un remontaje de explotación inicial de un núcleo de caliza formado por siete objetos, entre ellos un denticulado (nivel Ja, Abric Romaní, Barcelona).

la panoplia de objetos y utensilios empleados por estas comunidades, y que excepcionalmente se han recuperado en éste y algún otro yacimiento (Thieme, 1997; Carbonell y Castro-Curel, 1992). Lamentablemente, la excepcionalidad en la conservación de materiales orgánicos nos impide hacernos una idea real de los utensilios que estas comunidades elaboraban, ya que, en buena medida, los hechos en piedra sirvieron para fabricar otras herramientas. A su vez, demuestra su habilidad para el trabajo de otros materiales además de la piedra. Ello unido a la identificación del trabajo de la piel, permite destacar las capacidades técnicas de las mismas. Por último, una mayor presencia de deformaciones no ligadas a actividades directamente implicadas en el consumo de alimentos, como son las deformaciones relacionadas con acciones de carnicería, puede señalar que en las ocupaciones del nivel Ja se desarrollaron actividades más complejas que, presumiblemente, tendrían lugar en campamentos estables.

No se ha observado ninguna clara diferencia con respecto a la intensidad del trabajo o a los materiales trabajados entre los objetos retocados y las lascas. Los filos naturales a partir de $2 \mathrm{~cm}$ sirvieron para cualquiera de las acciones señaladas sobre los materiales citados. Tan solo se ha observado un predominio entre los denticulados del trabajo transversal sobre madera. Siguiendo con los objetos configurados, destaca también su participación en actividades de carnicería, por lo que los denticulados serían objetos versátiles, pero a la vez especializados en el trabajo sobre madera.

La morfología de arista activa utilizada corresponde a los diedros, tanto rectos, convexos como cóncavos. Los posibles triedros naturales que se obtienen en las lascas no son utilizados y en la configuración de denticulados, donde existe una asociación de diedros cóncavos y triedros, sólo se ha podido reconocer el trabajo de los primeros. Este resultado concuerda con la ausencia total de configuraciones de puntas o la talla predeterminada de lascas apuntadas. Esto implicaría que no precisarían la intervención de estos objetos o bien que serían otros útiles en algún material perecedero los encargados de dicha tarea. Se podría pensar en puntas sobre madera, recuperadas excepcionalmente en algunos yacimientos, ya que en el Abric Romaní sí sobresale la configuración denticulada que parece estar muy ligada al trabajo transversal sobre madera, precisamente el movimiento para fabricar puntas.

Es difícil hablar de la intensidad de trabajo, ya que el grado de deformación del útil depende mucho del material sobre el que actúa. No obstante en los objetos donde se ha identificado el trabajo sobre materia dura-que genera mayores deformacio-

T. P., 58, n. $^{\circ} 1,2001$ 



2

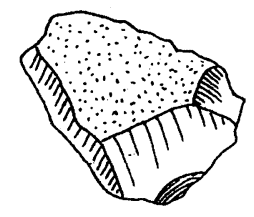

3
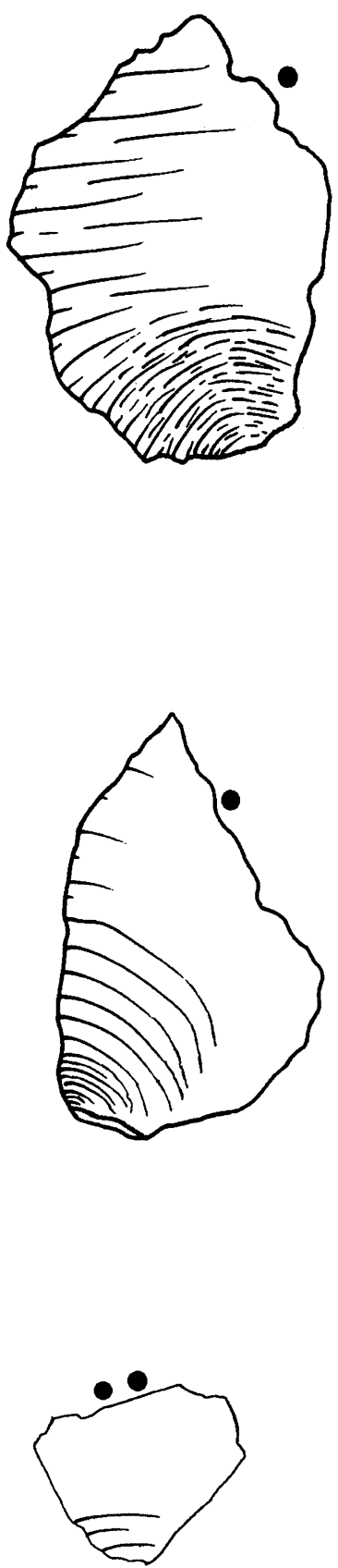
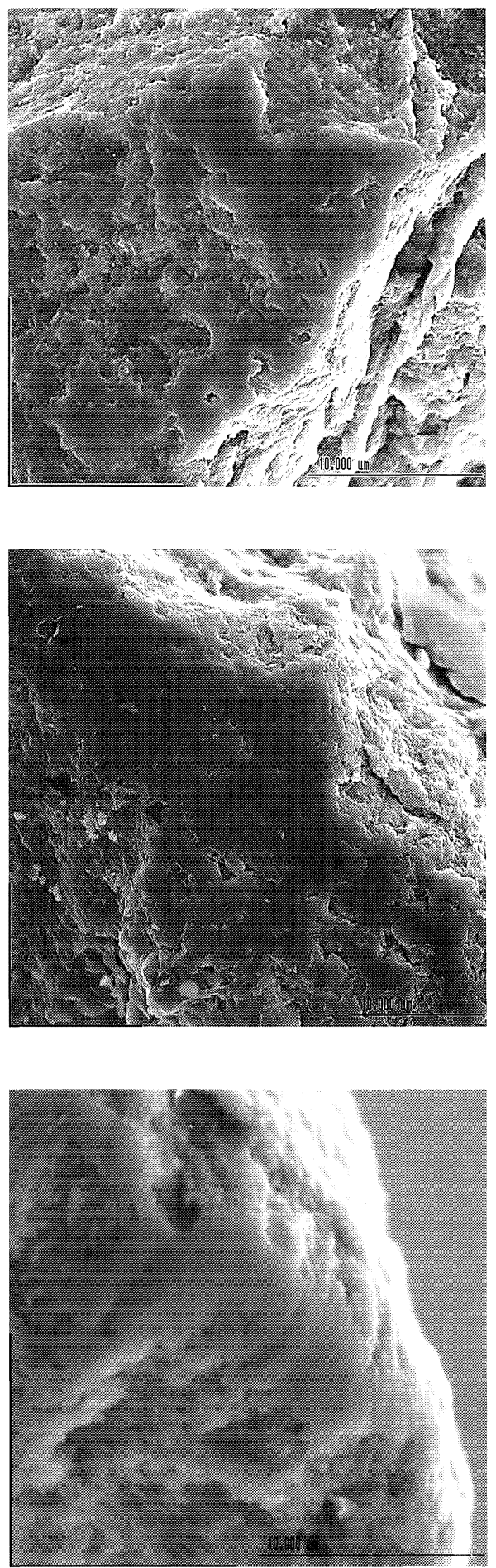

Fig. 10. Ejemplos de deformaciones por uso en el nivel Ja (Abric Romaní, Barcelona). Objeto 1, denticulado: deformación que atribuimos a una actividad de carnicería en donde se rozaba hueso. Objeto 2, denticulado: deformación muy desarrollada que atribuimos a un trabajo de dirección transversal/oblicua con madera fresca. Objeto 3, lasca: deformación con dirección transversal que atribuimos al trabajo con piel. 
nes en menor lapso de tiempo como la madera- se observan deformaciones limitadas a ciertas zonas del útil, por lo que hablaríamos de trabajos concretos. A su vez, tan solo en uno de los objetos estudiados, un denticulado, se advierte el uso independiente de dos zonas para trabajar dos materiales distintos. Hemos atribuido unas deformaciones a una acción de despellejar y otras a una acción transversal sobre madera. El útil se fabricaba para solventar una necesidad inmediata a tenor de su reducida intensidad de uso y de su escaso reaprovechamiento. Esta conclusión coincide con la ausencia, ya señalada, de intensidad de retoque y reavivamiento en los objetos configurados.

Por otra parte, no parece que las áreas del interior del abrigo se seleccionaran según actividades determinadas, más bien, en todas las zonas principales de acumulación se trabajaron los mismos materiales. En los grupos de remontaje cuyos objetos se dispersan por distintas áreas del abrigo, no se observa una relación entre segregación y usos, ni podemos hablar de que alguna zona del abrigo destaque por acoger el trabajo de un determinado material.Asimismo, en cada punto del abrigo en que identificamos una secuencia de talla mediante los remontajes, se identifica también la utilización, de los objetos allí obtenidos (Fig. 10).

Los datos expuestos, junto con los resultantes de la reconstrucción del proceso de producción lítica, nos permiten inferencias interesantes, como: 1) considerar potencialmente útiles todas aquellas lascas que, como mínimo, cuentan con un filo superior a $2 \mathrm{~cm}$ de longitud. 2) Los diedros son las morfologías aprovechadas para intervenir en todas las acciones posibles y para trabajar una amplia variedad de materiales. 3) La perfecta adecuación de la morfología de las lascas para los usos exigidos se corresponde perfectamente con la tecnología de estas comunidades, dirigida a la producción de lascas. 4) Tan solo se observa una exigencia morfológica relacionada con un uso específico; la morfología denticulada. Los denticulados, aunque versátiles, parecen concebidos para un trabajo transversal sobre madera. 5) Esta demanda se solventó con la elaboración de un útil adecuado para esta necesidad, al seleccionar lascas carenadas y, preferentemente, con asimetría lateral. Este tipo de lascas se obtiene de manera recurrente mediante el sistema de explotación identificado, Bifacial Centrípeto. 6) Por tanto, se observa una capacidad tecnológica capaz de fabricar los útiles adecuados según las necesidades.

\section{CONCLUSIONES}

La reconstrucción del proceso de producción lítica definida a partir del registro del nivel Ja señala cómo el abrigo, durante este momento, acogió ocupaciones de larga duración. Independientemente de las altas densidades de material recuperado, palimpsestos que complican la discriminación de episodios singulares, la identificación, aunque fragmentada, de todas las secuencias de explotación posibles, la recuperación de procesos de explotación casi completos en el interior y la interrelación, por medio del desplazamiento de objetos de todo el espacio ocupado, indica procesos técnicos intensos y prolongados. La capacidad de las comunidades de neandertales de organizar y estructurar asentamientos estables se pone habitualmente en duda (Simek, 1987; Klein, 1995; Mellars, 1996; Pettit, 1997), pero el nivel estudiado muestra patrones conductuales a la hora de ocupar y organizar las actividades en el interior de los campamentos. Se observa la discriminación de la ocupación del abrigo entre zonas centrales y marginales. Las últimas recibieron los desechos de las zonas principales y, probablemente, sustentaron algunas actividades especiales o intensas. Las zonas centrales se organizaron en torno a hogares, en donde se llevaron a cabo todo tipo de actividades que calificamos como domésticas por la ausencia de intensidad o especialización.

En este tipo de ocupaciones se han identificado distintas estrategias de aprovechamiento de los recursos líticos del entorno. Se observa, en el tratamiento de los recursos, un patrón sustentado en una gestión económica. Tanto el sílex como la caliza de buena calidad sufren una explotación máxima, los núcleos no se abandonan hasta su agotamiento y fragmentos espesos o lascas carenadas se reaprovechan en secuencias de explotación. En situaciones de estrés de disponibilidad de estos materiales se utiliza el cuarzo abundante en la zona. A su vez, se han recuperado varios bloques de sílex de tamaño grande en los que apenas se ha intervenido. Responderían a una estrategia de almacenamiento de recursos que se documenta ampliamente en yacimientos de este periodo (Conard y Antler, 1998).

No obstante, a pesar de que la economía de recursos es uno de los aspectos más destacados, no se observa intensos o continuos procesos de reconfiguración o reavivamiento de los objetos. Su disponibilidad se asegura con la explotación cuidadosa de los núcleos, que sólo se intervienen para producir útiles cuando urgen. Por tanto, hay conciencia

T. P., 58, n. ${ }^{\circ} 1,2001$ 
de unas necesidades futuras y estas se afrontan con una dilatada gestión de los núcleos, que se han de considerar como reserva de útiles. Pero no parece que exista una anticipación a las necesidades, sino que conocen el amplio abanico de las mismas, por habituales, y para resolverlas la producción se redirige constantemente. Así, por ejemplo, los denticulados serían concebidos para el trabajo con madera, un recurso que sería explotado intensamente en la zona del abrigo, como demuestra el análisis funcional. Esta necesidad favorece que este objeto sea dominante en el yacimiento y que se introduzcan en el abrigo denticulados configurados ya de fuera, pero no impide que el mismo útil pueda, en caso necesario, participar en otras actividades.

En definitiva, la tecnología de estas comunidades se sustentaba en unos procesos técnicos recurrentes, pero flexibles, y en un utillaje polifuncional, pero con un diseño predeterminado para los denticulados. Nos preguntábamos si la función dirigía la producción: tan solo entre denticulado y trabajo de madera vemos esta relación que implica la aptitud para reconocer y resolver anticipadamente necesidades. Por tanto, el registro del nivel Ja permite atribuir a las comunidades del Paleolítico Medio en el Abric Romaní una organización de la producción flexible pero planificada que relacionamos con una economía de amplio espectro, que no es sinónimo de arbitrariedad.

\section{BIBLIOGRAFÍA}

ANDERSON-Gerfaud, P. (1990): "Aspects of behaviour in the Middle Palaeolithic: functional analysis of stone tools from Southwest France". En P. Mellars (ed.): The Emergence of Modern Humans: an archaeological perspective. Edinburgh University Press. Edinburgh: 389-418.

Bartrolí, R.; Cebrià, A.; Muro, I.; Riu-Barrera, E. y VAquero, M. (1995): A frec de ciència. L'Atles d'Amador Romaní i Guerra. Ayuntamiento de Capellades. Capellades.

Beyries, S. (1987): Variabilité de l'industria lithique au moustérien. Approche fonctionnelle sur quelques gisements française. British Archaeological Report, 328. Oxford.

BEYRIES, S. y BoËDA, E. (1983): "Étude technologique et traces d'utilisation des 'éclats débordants' de Corbehem (Pas-de-Calais)”. Bulletin de la Société Préhistorique Française, 80: 275-279.

BINFORD, L.R. (1980): “Willow smoke and dogs' tails: hunter-gatherer settlement systems and archaeological site formation". American Antiquity, 45, 1: 4-20.

Bischoff, J.L.; Julià, R. y MoRA, R. (1988): “Uranium-
Series dating of the Mousterian occupation at Abric Romaní”. Nature, 332: 68-70.

Bischoff, J.L.; Ludwig, K.; García, J.F.; Carbonell, E.; Vaquero, M.; StafFord, T.W. y Jull, A.J.T. (1994): "Dating of the basal aurignacian sandwich at Abric Romaní (Catalunya, Spain) by Radiocarbon and Uranium-Series". Journal of Archaeological Science, 16: 553-576.

BoËDA, E. (1993): "Le débitage discoïde et le débitage levallois récurrent centripète". Bulletin de la Société Préhistorique Française, 90: 392-404.

BuRJACHS, F. y JuLIÀ, R. (1994): “Abrupt Climatic Changes during the Last Glaciation Based on Pollen Analysis of the Abric Romaní, Catalonia, Spain". Quaternary Research, 42: 308-315.

Carbonell, E. y Castro-Curel, Z. (1992): "Palaeolithic Wooden Artefacts from the Abric Romaní (Capellades, Barcelona, Spain)". Journal of Archaeological Science, 19: 707-719.

Carbonell, E.; Cebrià, A.; Allué, E.; Cáceres, I.; Castro, Z.; Díaz, R.; Esteban, M.; Pastó, I.; Ollé, A.; RodríGUEZ, X.P.; Rosell, J.; SAla, R.; Vallverdú, J.; VAQUERO, M. y VERGÈs, J.M. (1996): "Behavioural and organizational complexity in the Middle Paleolithic from the Abric Romaní". En E. Carbonell y M. Vaquero (eds.): The Last Neandertals, The First Anatomically Modern Humans; a Tale about the Human Diversity. Universitat Rovira i Virgili. Tarragona: 385-434.

Carbonell, E.; Mosquera, M.; Ollé, A.; Rodríguez, X.P.; Sala, R.; Vaquero, M. y Vergès, J.M. (1992): "New elements of the logical analytic system". First International Meeting on technical System to Configure Lithic Objects of scarce elaboration (Montblanc, 1992). $\mathrm{Ca}$ hier Noir, 6. Laboratori d'Arqueologia de la Universitat Rovira i Virgili/Reial Societat Arqueològica Tarraconense. Tarragona.

CONARD, N. y AdLer, D. (1998): "Lithic reduction and hominid behavior in the Middle Palaeolithic of the Rhineland". Journal of Anthropological Research, 53: 147-174.

CZiesla, E.; Eickhoff, S.; Arts, N. y Winter, D. (eds.) (1990): The Big Puzzle. International Symposium on Reffiting Stone Artefacts. Holos. Bonn.

Dibble, H.L. (1995): "Middle Palaeolithic Scraper Reduction: Background, Clarification and Review of the Evidence to Date". Journal of Archaeological Method and Theory, 2(4): 299-368.

Geneste, J.M. (1988): "Les industries de la Grotte Vaufrey: technologie du débitage: économie et circulation de la matière prémière litique". En J.-P. Rigaud (ed.): La Grotte Vaufrey à Cenac et Saint Julien (Dordogne): Paléoenvironnement, chronologie et activités humaines. Societé Préhistorique Française. Paris: 441-517.

Giralt, S. y JuLIÀ, R. (1996): "The sedimentary record of the Middle-Upper Palaeolithic transition in the Capellades Area (NE, Spain)”. En E. Carbonell y M. Vaquero 
(eds.): The Last Neandertals, The First Anatomically Modern Humans; a Tale about the Human Diversity. Universitat Rovira i Virgili. Tarragona: 385-434.

Guilbaud, M. (1995): "Introduction sommaire au concept de champ opératoire". Cahier Noir, 7: 121-133.

JARDÓN, P. (1990): "La metodología del análisis traceológico y su aplicación a conjuntos líticos prehistóricos". Saguntum. 23: 9-37.

KeELEY, L.H. (1980): Experimental determination of stone tool uses: a microwear analysis. University of Chicago Press. Chicago.

KLEIN, R.G. (1995): "Anatomy, Behavior and Modern $\mathrm{Hu}-$ man Origins". Journal of World Prehistory 9(2): 167198.

KuHN, S.L. (1989): "Hunter-Gatherer foraging organitzation and strategies of artifact replacement and discard". En D. Amick y R. Mauldin (eds.): Experiments in Lithic Technology. British Archaeological Report, 528: 33-46. Oxford.

- (1992): "On planning and curated technologies in the Middle Paleolithic". Journal of Anthropological Research, 48: 186-214.

- (1995): Mousterian Lithic Technology. An Ecological Perspective. Princeton University Press. Princeton.

- (1998): "The economy of lithic raw materials and the economy of food procurament". En J.P. Brugal, L. Meignen y M. Patou-Mathis (eds.): Économie préhistorique; les comportements de subsistence au Paléolithique. APDCA. Sophia Antipolis: 215-226.

MARKs, A.E. (1988): "Early mousterian settlement patterns in the Central Negev. Israel: their social and economic implicationes". L'Homme de Néandertal, 6, La Subsistènce. E.R.A.U.L. Liège: 115-126.

Mellars, P. (1996): The Neanderthal Legacy. AnArchaeological Perspective from Western Europe. Princeton University Press. Princeton.

ODELL, G.H. (1979): "A new improved system for the retrieval of functional information from microsopic observation of chipped stone tools". En B. Hayden (ed.): Lithic use-wear. Academic Press. New York: 239-244.

PetTit, P.B. (1997); "High resolution Neanderthals?. Interpreting Middle Paleolithic intrasite spatial data". World Archaeology, 9(2): 208-224.

Roebroeks, W.; Kolen, J. y Rensink, E. (1988): “Planning depth, anticipation and the organization of the Middle Paleolithic technology: the "arcaic natives" meeth Eve's descendants". Helinium, 28: 17-34.
Roebroeks, W.; Kolen, J.; Van Poecke, M. y Van Gijn, A. (1997): “'Site J': An early weichselian (middle paleolithic) flint scatter at Maastricht-Belvedere, The Netherlands". Paleo, 9: 143-172.

Rolland, N. y Dibble, H.L. (1990): "A new synthesis of Middle Paleolithic variability". American Antiquity, 55: 480-499.

Sala, R.; Giralt, S; Ollé, A. y Vergès, J.M. (1998): “The process of wear formation. Archaeological approach". En L. Longo, R. Sala y C. Gutiérrez (coords.): Workshop 17: Functional analysis of lithic artefacts: current state of the research. XIII International Congress of Prehistoric and Protohistoric Sciences, 6, II. A y A. Antoniazzi, J.L.Arsuaga, J.M ${ }^{a}$ Bermúdez de Castro, E. Carbonell, E. Cavallini, S. di Lernia, F. Fontana, C. Gutiérrez, L. Longo, G. Manzi, S. Milliken, L. Oosterbeek, V. Pavukova, M. Peresani, V. Pesce, K. Pizchelauri, L. Prati, R. Sala y C. Peretto (eds.).A.B.A.C.O. Forlí: 1133-1141.

SIMEK, J.F. (1987): "Spatial order and behavioural change in the French Palaeolithic". Antiquity, 61: 25-40.

TEXIER, J.P.; Brugal, J.P.; LEMORINI, C. y WiLSON, L. (1998): "Fonction d'un site du Paléolithique moyen en marge d'un térritoire. L'Abri de La Combette (Bonnieux, Vaucluse)". En J.P. Brugal; L. Meignen y M. PatouMathis (eds.): Économie préhistorique; les comportements de subsistence au Paléolithique. APDCA. Sophia Antipolis: 325-348.

THIEME, H. (1997): "Lower Palaeolithic hunting spears from Germany”. Nature, 385: 769-771.

VAQUERO, M. (1999): "Intrasite spatial organization of lithic production in the Middle Palaeolithic: the evidence of the Abric Romaní (Capellades, Barcelona)".Antiquity, 73: 493-504.

Vaquero, M.; Alegre, P.; Galindo, E.; Martínez, K.; Martorell, S.; Plana, X.; Rando, J.M.; García-ANTÓn, D.; Mallol, C. y Morant, N. (1996): “Organización espacial de la producción lítica en un yacimiento del Paleolítico Medio: niveles I y J del Abric Romaní (Capellades, Barcelona)". En R. Balbín y P. Bueno (eds.): II Congreso de Arqueología Peninsular. IPaleolítico y Epipaleolítico: 35-49.

ZILHÃo, J. y D'ERRICO, F. (1999): “The chronology and taphonomy of the earliestAurignacian and its implications for the understanding of Neandertal extinction". Journal of World Prehistory, 13(1): 1-68. 